body was gently lifted out with demonstrations of affection by four men. As they bore it towards the grave, which was more or less circular in shape and some $4 \frac{1}{2}$ feet deep, I could clearly see that the cadaver, without any cords or bindings whatever around it, was still held by rigor mortis in the attitude in which it had died. The body was deposited in its last resting-place in this sitting attitude without any unflexing of its limbs. Over it were laid several grass petticoats, but no other grave furniture so far as I observed, before the earth was filled in.

It seems to me not improbable that where among primitive peoples the dead were not retained long above ground after breathing their last, the contracted position, in which Death usually overtook his victims, stiffening limb and muscle in that attitude by the rigor mortis - a rigicity requiring force to abatecame to be adopted as the natural, if not magical, position for sepulture (whether laid on right or left side or set erect) rather than from any idea of the deceased's position when an embryo, or of "his returning to the womb of earth."

Deanway, Beaconsfield, Bucks.

Henry O. Forbes.

\section{The Choice of Wave-lengths for Achromatism in Telescopes.}

DURING the past summer, in the Transactions of the Optical Society, Mr. J. W. Gifford has directed attention anew to the question as to the two wave-lengths most suitable for achromatising telescope objectives. Mr. Gifford has constructed telescopes in which the paraxial focal length for the $D$ and $E$ lines is the same, and, judging by the performance of such objectives, he considers such a choice superior to the more customary choice of the $\mathrm{C}$ and $\mathrm{F}$ lines. By a different path I have been led to a similar judgment, at least for telescopes of large aperture.

It is the purpose of this note to show that it is possible to meet the objection, which was made in the discussion, to the closeness of the $D$ and $E$ lines, and also to indicate certain relations which exist between the wave-lengths selected for achromatising and the type of achromatisation which results. The results are for a thin contact pair of hard crown and dense flint, and are deduced with the aid of Hartmann's interpolation formula.

The result of making the focal length the same for

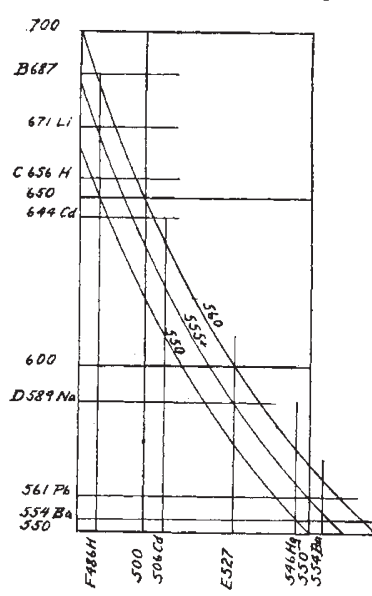
two different wave-lengths is to make the focal length a minimum for some wavelength intermediate between these two. On the blue side of this minimum the focal length increases more rapidly than it does on the red side, and as the wave-length of the minimum is made greater, the curve which represents the variation in focal length is made noticeably more flat. From two such curves with minimum wavelengths of $55^{\circ}$ and 560 millimicrons respectively, the data which is represented on the accompanyFrg. I. ing diagram (Fig. I) was obtained.

On the diagram the curve marked " 560 " represents all possible choices of wave-lengths which can be used to bring the minimum focal length of the achromatised doublet to a wave-length of $560 \mu \mu$. If, for example, one wishes to use the $\mathbf{E}$ line and to have the minimum at 560 , then one must make the focal length the same for 527 and for $600 \mu \mu$. Or, the choice of B and $F$ for achromatising will make the wave-length of minimum focal length just a trifle greater than $560 \mu \mu$. In a similar manner, the curve " 550 " represents all possible choices of wave-lengths which will give that value for the wave-length of the minimum focal length. The intermediate curve, marked " $555+$, ," is drawn with the same form as the other two and passes through the point of intersection of $D$ and $E$. This curve, then, represents the possible combinations of wave-lengths which will be equivalent to the combination of $\mathrm{D}$ and $\mathrm{E}$.

Evidently the red lithium line and the $\mathrm{F}$ hydrogen line will give very nearly the same result as the combination of $D$ and $E$, and there does not seem to be any other convenient combination which will so serve. However, hydrogen tubes are easily obtained, and a lithium coloured bunsen flame can be maintained for hours at a time by wrapping around the burner a small square of paper which has been previously soaked in a solution of lithium chloride and then dried, feeding the paper slowly up into the flame as it is burned away.

I may add that the aberrations should be corrected for a wave-length in the neighbourhood of that for which the focal length is a minimum. If the hydrogen tube be contaminated with a little mercury, it will furnish the mercury line at $546 \mu \mu$, by means of which a value of the index of refraction could be obtained not differing greatly from that at the minimum.

Brace Laboratory,

University of Nebraska, September Io.

\section{T. Townsend Smith.}

\section{Lake Victoria and the Flow of the Yala River.}

Wiтн considerable diffidence I venture to offer an explanation of the diurnal current change described by Dr. G. D. Hale Carpenter in NATURE of August 30, p. 3II. In equatorial regions a twelve-hourly barometric oscillation attains its maximum amplitude of approximately $0.9 \mathrm{~mm}$. of mercury. The maxima occur daily at about 9.IO A.M. and P.M. Thus, in the absence of major barometric fluctuations, the pressure is on the decrease from about 9 A.M. until early in the afternoon at a time corresponding approximately with the time of reversal of the current. It follows that the lake level will be rising during this period, and hence an overflow into the deltaic marsh. The volume of river water entering the swamp should be sufficient to account for the reversal occurring about one hour previous to the time of the barometric minimum.

A second factor that should augment this effect is differential evaporation between lake and swamp. The shallow water of the latter would probably grow warmer during this period and lose more by evaporation than the deep water of the lake.

Further information as to the behaviour of the current during the night--the time of the diurnal rainfall (if this be regular) and the time thereafter when the river level rises-might materially assist in solving the problem. NORMAN L. Silvester.

Aber, Cavendish Ave., Finchley, N.3.

WiTH reference to Dr. Hale Carpenter's letter (NATURE, August 30, p. 3II) on the subject of Lake Victoria and the flow of the Yala River, the following considerations occur to me. There is a fairly regular diurnal fluctuation in the waters of the lake. At the 